\title{
OPEN Uncovered self-expandable metal stents for the treatment of refractory benign colorectal anastomotic stricture
}

\author{
Ji Taek Hong ${ }^{1}$, Tae Jun $\mathrm{Kim}^{2}$, Sung Noh Hong $\mathbb{1}^{2}$, Young-Ho Kim², Dong Kyung Chang ${ }^{2}$ \& \\ Eun Ran Kim ${ }^{2 \bowtie}$
}

Self-expandable metal stent (SEMS) placement has been suggested as a therapeutic modality for treating benign colorectal strictures. Covered stents are generally used, given the concerns regarding the efficacy and safety of uncovered stents. Hence, few studies have evaluated the efficacy and safety of uncovered SEMSs (UCSEMSs) in patients with refractory benign colorectal anastomotic strictures. In this study, 12 patients with postoperative benign symptomatic anastomotic strictures refractory to pneumatic dilation (range, 2-9) and transient indwelling-covered SEMSs were treated using UCSEMS. All enrolled patients were men (mean age, 61 years). Stent placement was successful in all 12 patients, and early clinical success was achieved in 11 (92\%) patients. Four patients $(25 \%)$ showed successful clinical outcomes without further intervention, but eight patients $(75 \%)$ were clinically unsuccessful, and showed stricture recurrence or functional obstructive symptoms. Three patients underwent surgery, and the remaining five patients required repeat stent procedures. Despite the high reobstruction rate, the median follow-up period after UCSEMS placement was 16.7 months, demonstrating that UCSEMS may be able to achieve medium-term symptom relief without any complications. Therefore, UCSEMS may be an alternative option in exceptional circumstances in carefully selected patients, where invasive surgical treatments, such as stoma diversion, are not an option, thereby improving patients' quality of life.

Benign colorectal obstruction can be caused by various factors related to diverticulosis, inflammation, ischemia, radiation, or anastomosis. Among these factors, anastomotic stricture is one of the most common complications of colorectal surgery ${ }^{1}$, with the incidence of anastomotic stricture or stenosis after colorectal surgery ranging between 0 and $30 \%{ }^{2-4}$. Patients with clinically significant strictures typically exhibit partial or complete bowel obstruction.

Clinically significant colorectal, colocolic, or ileocolic strictures can be managed by minimally invasive methods, either endoscopically or radiologically. Endoscopic balloon dilation is reportedly successful in $88-100 \%$ of benign cases ${ }^{2,5,6}$, whereas endoscopic transanal resection of strictures has been described for managing highgrade anastomotic strictures ${ }^{6}$. However, commonly used endoscopic treatments are often ineffective due to the use of a balloon, and have a high recurrence rate of $30-88 \%$, as well as refractoriness in $>20 \%$ of cases ${ }^{6-10}$, with such refractory strictures often requiring surgical revision.

Self-expandable metal stent (SEMS) placement is a widely used endoscopic treatment modality for strictures ${ }^{11}$. However, SEMS treatment was originally established to palliate malignant colorectal obstruction or as a bridge to surgery ${ }^{12-15}$. Recently, SEMS placement has also been suggested as a therapeutic modality for the relief of benign colorectal strictures. However, data regarding the use of SEMSs in patients with benign colorectal strictures have been obtained from heterogeneous studies, and the efficacy, safety, and long-term patency of SEMSs in these patients remains controversial ${ }^{11,12,16-20}$.

In addition, although both fully covered SEMS (FCSEMS) and uncovered SEMS (UCSEMS) have advantages and disadvantages, FCSEMSs are primarily used for benign strictures because of the reduced local tissue response ${ }^{16}$. To date, limited studies have examined the efficacy and safety of UCSEMS placement in patients with

${ }^{1}$ Department of Internal Medicine, Ewha Womans University College of Medicine, Seoul, Korea. ${ }^{2}$ Division of Gastroenterology, Department of Medicine, Samsung Medical Center, Sungkyunkwan University School of Medicine, 81 Irwon-ro, Gangnam-gu, Seoul 06351, Republic of Korea. ${ }^{\bowtie}$ email: er.kim@samsung.com 


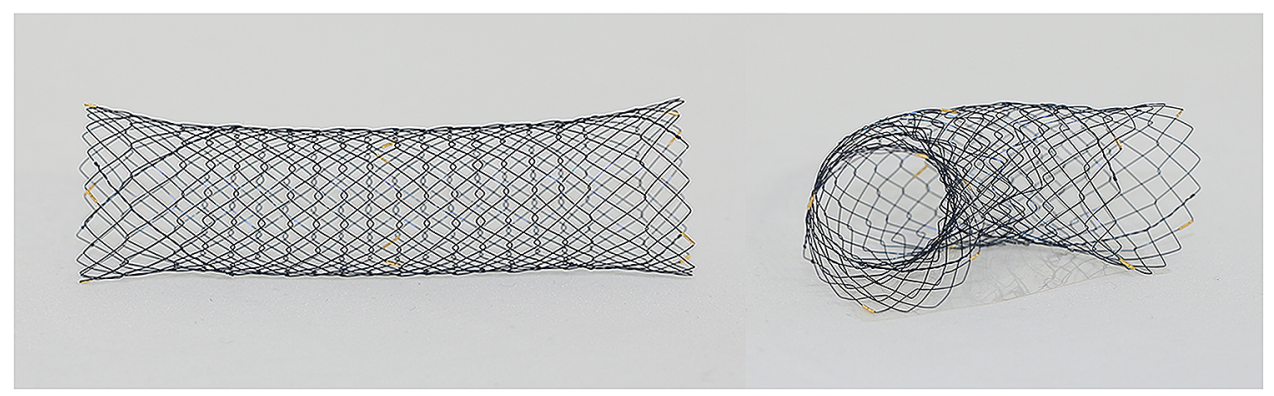

Figure 1. Uncovered self-expandable metal stents.

refractory benign colorectal strictures, and the limited available data have been obtained from a heterogeneous study ${ }^{17}$. Recently, biodegradable and drug-eluting stents have also been attempted or studied ${ }^{21-25}$. Despite their considerable advantages and good anecdotal results, their application in the large bowel is unlicensed, and further evidence is needed until they can be used widely. Furthermore, specific indications for covered and uncovered stents in patients with benign colorectal stenosis have not been well established ${ }^{26,27}$. Therefore, this study aimed to detail our experience with attempted UCSEMS placement for the treatment of refractory benign colorectal anastomotic strictures in a homogeneous group of patients, with the aim to offer an alternative treatment option and avoid invasive surgical treatment.

\section{Methods}

This retrospective study included all patients treated for symptomatic postoperative colorectal anastomotic strictures at our institution. All patients were identified from the prospective database of our hospital. Between October 2012 and December 2017, 12 male patients (mean age: 61 \pm 13.2 [43-89] years) with refractory benign colorectal anastomotic strictures underwent UCSEMS placement. The requirement for patient consent was waived given the retrospective nature of the study (approval ID: SMC2018-12-089).

All endoscopic stent placements were performed under fluoroscopic guidance, and all stents were inserted by an experienced, board-certified interventional endoscopist (E.R.K.). The patients were placed in either the supine or left lateral decubitus position. Colon cleansing was achieved using oral polyethylene glycol and/or enemas. After visualization of the obstructed area with colonoscopy (12.2-mm outer diameter, Evis Lucera Colonovideoscope CF-H260AL/I; Olympus, Tokyo, Japan), a water-soluble contrast agent was injected to identify the stricture lesion and measure the length of the stricture. The length of the stent was chosen to cover the entire stricture lesion and extend beyond each end of the obstruction by at least $1-2 \mathrm{~cm}$. Stenting was not performed when the stricture was located less than $4 \mathrm{~cm}$ from the anal verge (distal rectum), or when the stricture was $>8 \mathrm{~cm}$. Once a guidewire (0.025-in. VisiGlide-2TM; Olympus Co., Tokyo, Japan) was positioned through the stricture area, a UCSEMS (length, 6 or $8 \mathrm{~cm}$; diameter, $24 \mathrm{~mm}$; BONA, Standard Sci Tech Inc., Seoul, South Korea or MI Tech, Seoul, South Korea) was placed (Fig. 1). Plain abdominal radiographs were obtained $24 \mathrm{~h}$ after the procedure to assess obstruction relief, as well as to confirm stent expansion and position.

Technical success was defined as adequate UCSEMS placement at the first attempt, with correct positioning and complete stent deployment at the stricture site confirmed using fluoroscopy. Early clinical success was defined as obstructive symptom relief and colorectal decompression persisting for a minimum of 3 days in the absence of endoscopic reinterventions or surgical procedures. Safety outcome was defined as the occurrence of complications; those leading to clinical failure, perforation, or a change in the treatment modality were labeled as major complications, whereas fecal incontinence, pain, foreign body sensation, hyperplastic tissue overgrowth, and self-limiting bleeding were labeled as minor complications. Early complications were defined as those occurring within 30 days after stent placement, whereas late complications were defined as those occurring over 30 days after stent placement.

Clinical failure was defined as the occurrence of obstructive signs and/or recurrence of symptoms any time after stent placement, which required reintervention or a surgical procedure. Stent migration was defined as either endoscopic visualization or radiographic evidence of stent movement from the initial position, total stent evacuation, or both. Clinical success was defined as persistent symptom improvement during follow-up, in the absence of reintervention or surgical treatment. The results are presented as mean (standard deviation) and median (range) unless otherwise stated. All analyses were performed using a statistical software package (SPSS 12.0 for windows, SPSS Inc., Chicago, IL, USA).

The study was approved by the Institutional Review Board of Samsung Medical Center (IRB No. SMC 201812-089), and the study was performed in accordance with the principles of the Declaration of Helsinki. The offlabel indication of the procedure was fully explained to the patient, and written informed consent was obtained from all patients who received this treatment.

\section{Results}

Twelve patients with benign colorectal strictures secondary to postoperative anastomotic strictures were treated using metal-uncovered stents between October 2012 and December 2017. All cases were refractory to at least two balloon dilations, and 6 of the 12 patients underwent covered SEMS insertion prior to UCSEMS insertion. In all 


\begin{tabular}{|c|c|c|c|c|c|c|c|}
\hline Sex/age (years) & Etiology & Surgery & $\begin{array}{l}\text { Preoperative } \\
\text { therapy }\end{array}$ & $\begin{array}{l}\text { Postoperative } \\
\text { therapy }\end{array}$ & $\begin{array}{l}\text { Degree of } \\
\text { obstruction }\end{array}$ & $\begin{array}{l}\text { Previous endoscopic } \\
\text { treatment }\end{array}$ & $\begin{array}{l}\text { Diverticular } \\
\text { disease }\end{array}$ \\
\hline $\mathrm{M} / 57$ & Rectal Ca & $\begin{array}{l}\text { SILS-LAR c protec- } \\
\text { tive ileostomy }\end{array}$ & Neoadjuvant CCRT & Adjuvant CT & Total & \begin{tabular}{|l|} 
Balloon dila- \\
tions + FCSEMS \\
( 22 days: removal \\
due to anal pain \\
caused by stent \\
movement)
\end{tabular} & No \\
\hline $\mathrm{M} / 66$ & Rectal Ca & LAR & - & Adjuvant CCRT & Total & Balloon dilations & No \\
\hline $\mathrm{M} / 58$ & Rectal Ca & $\begin{array}{l}\text { HALS-LAR c protec- } \\
\text { tive ileostomy }\end{array}$ & Neoadjuvant CCRT & Adjuvant CT & Subtotal & $\begin{array}{l}\text { Balloon dila- } \\
\text { tions +FCSEMS } \\
\text { (14 days: stent } \\
\text { migration) }\end{array}$ & No \\
\hline $\mathrm{M} / 73$ & Rectal Ca & $\begin{array}{l}\text { LAR c protective } \\
\text { ileostomy }\end{array}$ & Neoadjuvant CCRT & - & Subtotal & Balloon dilations & No \\
\hline $\mathrm{M} / 55$ & Rectal Ca & $\begin{array}{l}\text { LAR c protective } \\
\text { ileostomy }\end{array}$ & - & $\begin{array}{l}\text { Adjuvant CT Pallia- } \\
\text { tive CT }\end{array}$ & Total & $\begin{array}{l}\text { Balloon dila- } \\
\text { tions + FCSEMS } \\
\text { (15 days: removal } \\
\text { due to anal pain } \\
\text { caused by stent } \\
\text { movement) }\end{array}$ & No \\
\hline $\mathrm{M} / 57$ & Sigmoid colon $\mathrm{Ca}$ & AR & Neoadjuvant CCRT & - & Subtotal & Balloon dilations & No \\
\hline $\mathrm{M} / 43$ & $\begin{array}{l}\text { Pancreatitis, pseu- } \\
\text { docyst }\end{array}$ & $\begin{array}{l}\text { Rt colectomy c } \\
\text { ileostomy }\end{array}$ & - & - & Total & Balloon dilations & No \\
\hline $\mathrm{M} / 89$ & Sigmoid colon Ca & AR & - & - & Total & Balloon dilations & No \\
\hline $\mathrm{M} / 45$ & $\begin{array}{l}\text { Rectosigmoid colon } \\
\mathrm{Ca}\end{array}$ & $\begin{array}{l}\text { SILS-LAR c protec- } \\
\text { tive ileostomy }\end{array}$ & Neoadjuvant CCRT & - & Subtotal & $\begin{array}{l}\text { Balloon dila- } \\
\text { tions + FCSEMS } \\
\text { ( } 2 \text { days: stent migra- } \\
\text { tion) }\end{array}$ & No \\
\hline $\mathrm{M} / 51$ & $\begin{array}{l}\text { Rectosigmoid colon } \\
\mathrm{Ca}\end{array}$ & Hartmann operation & - & - & Subtotal & \begin{tabular}{|l} 
Balloon dila- \\
tions +FCSEMS \\
(47 days: stent \\
migration) \\
\end{tabular} & No \\
\hline $\mathrm{M} / 70$ & $\begin{array}{l}\text { Rectosigmoid colon } \\
\text { Ca }\end{array}$ & $\begin{array}{l}\text { SILS-AR c protective } \\
\text { ileostomy }\end{array}$ & - & Adjuvant CT & Total & Balloon dilations & Yes \\
\hline $\mathrm{M} / 72$ & Rectal Ca & $\begin{array}{l}\text { LAR c protective } \\
\text { ileostomy }\end{array}$ & - & - & Subtotal & $\begin{array}{l}\text { Balloon dila- } \\
\text { tions + FCSEMS } \\
\text { (14 days: stent } \\
\text { migration) }\end{array}$ & Yes \\
\hline
\end{tabular}

Table 1. Characteristics of patients undergoing uncovered metal stenting for benign anastomosis strictures. Ca.: cancer, SILS: single-incision laparoscopic surgery, LAR: low anterior resection, HALS: hand-assisted laparoscopic surgery, AR: anterior resection, CCRT: concurrent chemoradiotherapy, CT: chemotherapy, FCSEMS: fully covered self-expandable metal stent; c, with.

cases, previous endoscopic dilations with and without covered SEMS for temporary drainage had been unsuccessful, with the number of dilations ranging from 2 to 9 . The causes of treatment failure in the patients with a covered SEMS was anal pain caused by stent movement $(2 / 6,33 \%)$ and stent migration $(4 / 6,67 \%)$. All patients had symptoms of intestinal obstruction 24-48 h before UCSEMS insertion. Six patients (50\%) had complete obstruction, confirmed fluoroscopically using water-soluble contrast agent injection, and endoscopically through direct visualization. Histological analysis confirmed that all strictures were benign.

The baseline characteristics of the patients are presented in Table 1. The etiology of the obstruction was postsurgical anastomotic strictures in all patients. Six patients with rectal cancer underwent lower anterior resection with protective ileostomy, one patient with sigmoid colon cancer underwent the Hartmann procedure, one patient with rectal cancer underwent lower anterior resection without protective ileostomy, three patients with sigmoid colon cancer underwent laparoscopic anterior resection, and one patient with a pancreatic pseudocyst underwent right colectomy. Moreover, history of neoadjuvant chemoradiotherapy $(n=5)$, adjuvant chemotherapy $(n=5)$, and adjuvant chemoradiotherapy $(n=1)$ was observed.

All 12 patients (100\%) achieved technical success (Fig. 2) and underwent intraprocedural decompression immediately following stent insertion. Clinically and radiologically, UCSEMS successfully relieved obstruction in 11 patients (92\%). Early clinical success was achieved in 11 of the 12 (92\%) cases (Table 2). Subsequently, the patients underwent clinical and endoscopic follow-up, with a median follow-up period of 16.7 (1.7-35.37) months after UCSEMS placement. The follow-up period and outcomes for each patient are detailed in Table 3.

The outcomes of UCSEMS insertion were determined in all patients. In particular, among the 12 patients, 3 (25\%) underwent surgery and 4 (33\%) achieved clinical success without further intervention during a median follow-up period of 16.7 months. The remaining 5 patients required repeat stent procedures.

Migration was observed in $2(17 \%)$ of the 12 patients within the first 30 days. All instances of stent migration occurred in patients with partial intestinal obstruction from the time of diagnosis.

Reobstruction occurred in six patients (50\%) (mean period: 461 days [range: 155-1047 days]), and multiple additional stents were reinserted after reobstruction. Of these six patients, five who underwent restenting remained under observation at the outpatient clinic without recurrence or complications. One patient initially 

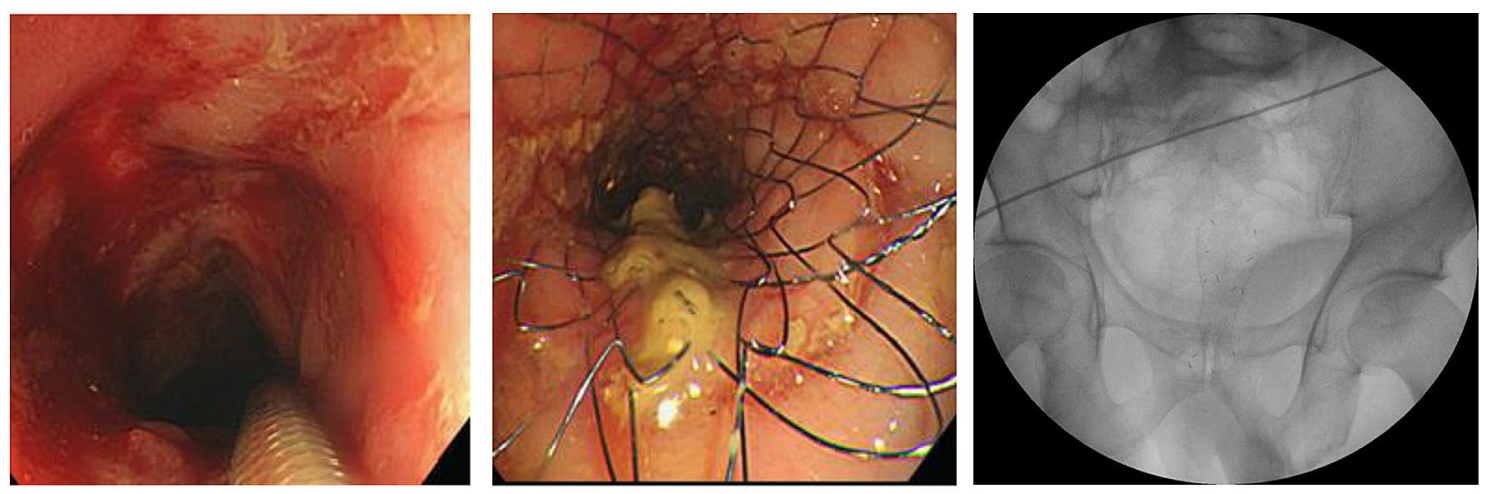

Figure 2. Endoscopic and fluoroscopic images showing successful insertion of an uncovered self-expandable metal stent for refractory benign colorectal anastomotic stricture.

\begin{tabular}{|c|c|c|c|c|c|c|}
\hline Sex/age (years) & $\begin{array}{l}\text { Reason for considering UCSEMS } \\
\text { insertion }\end{array}$ & Technical success & Early clinical success & Distance from $\mathrm{AV}(\mathrm{cm})$ & Stent length $(\mathrm{cm})$ & Stent diameter $(\mathrm{mm})$ \\
\hline $\mathrm{M} / 57$ & FCSEMS failure & Yes & Yes & 5 & 6 & 24 \\
\hline $\mathrm{M} / 66$ & Poor candidate for surgery & Yes & Yes & 10 & 6 & 24 \\
\hline $\mathrm{M} / 58$ & FCSEMS failure & Yes & Yes & 8 & 6 & 24 \\
\hline $\mathrm{M} / 73$ & Poor candidate for surgery & Yes & Yes & 7 & 6 & 24 \\
\hline $\mathrm{M} / 55$ & FCSEMS failure & Yes & Yes & 7 & 6 & 24 \\
\hline $\mathrm{M} / 57$ & Refusal of surgical treatment & Yes & Yes & 18 & 6 & 24 \\
\hline $\mathrm{M} / 43$ & Refusal of surgical treatment & Yes & Yes & 45 & 8 & 24 \\
\hline $\mathrm{M} / 89$ & Poor candidate for surgery & Yes & Yes & 15 & 6 & 24 \\
\hline $\mathrm{M} / 45$ & FCSEMS failure & Yes & No & 5 & 6 & 24 \\
\hline $\mathrm{M} / 51$ & FCSEMS failure & Yes & Yes & 12 & 4 & 24 \\
\hline $\mathrm{M} / 70$ & Poor candidate for surgery & Yes & Yes & 17 & 12 & 24 \\
\hline $\mathrm{M} / 72$ & $\begin{array}{l}\text { FCSEMS failure, poor candidate for } \\
\text { surgery }\end{array}$ & Yes & Yes & 8 & 6 & 24 \\
\hline
\end{tabular}

Table 2. Indications for UCSEMS insertion and early clinical outcomes. AV: anal verge, US: uncovered stent, CS: covered stent, TH: tissue hyperplasia.

underwent restenting but failed to maintain endoscopic stent patency and exhibited worsening of symptoms, for which elective surgical segmental resection was performed. A total of 9 SEMS reinsertions were performed in 5 of the 11 patients who maintained endoscopic stent patency as a result of restenosis (tissue ingrowth through the mesh) (Fig. 3). All re-occlusions were the result of epithelial hyperplasia, mucosal edema, and/or transmural fibrosis.

No major UCSEMS-related complications, such as perforation, occurred throughout the study period. Minor complications were observed in 3 of the 12 patients (25\%); one exhibited stent fracture and the other two exhibited hyperplastic tissue overgrowth. Stent fracture was incidentally noted during regular follow-up endoscopic examinations without any specific symptoms. At the median follow-up period of 16.7 months, 4 (25\%) of the 12 patients achieved clinical success.

Finally, three patients underwent surgery, one of whom failed to maintain endoscopic stent patency because of restenosis, and the two remaining patients experienced persistent functional obstruction despite successful additional stent replacement (median, 2.9; range, 6 days-5.6 months). Two patients eventually underwent surgery because of stent functional failure (Fig. 4).

\section{Discussion}

The use of SEMS for benign strictures remains controversial. Accordingly, SEMSs used for benign colorectal diseases are associated with higher rates of stent-related complications, such as perforation, stent migration, recurrent obstruction, bleeding, and mucosal overgrowth than those used for malignant diseases ${ }^{11-13,17,28-30}$. Although concerns regarding efficacy and safety have previously limited the use of SEMs, their use for benign diseases has been attempted ${ }^{18,20,31}$.

Covered stents are generally used for benign gastroduodenal or colorectal strictures, considering that uncovered stents may cause tissue embedding through the stent's metal meshwork during the follow-up period. In addition, UCSEMS cannot be removed; therefore, their use has always been intended as a bridge therapy to surgery or as a palliative therapy in patients with malignant strictures. However, covered stents have a considerable advantage in preventing granulation tissue formation ${ }^{32,33}$. Moreover, reports showing significant morbidity in patients with benign strictures who underwent UCSEMS placement have further limited their use. As a result, 


\begin{tabular}{|c|c|c|c|c|c|c|c|c|}
\hline Sex/age (years) & $\begin{array}{l}\text { Duration of luminal } \\
\text { patency (days) }\end{array}$ & Stent outcomes & $\begin{array}{l}\text { Endoscopic } \\
\text { reintervention } \\
\text { (time after stent } \\
\text { insertion) (days) }\end{array}$ & $\begin{array}{l}\text { Follow-up outcome } \\
\text { (time after stent } \\
\text { insertion) }\end{array}$ & Clinical failure & Clinical success & Operation & Stoma \\
\hline $\mathrm{M} / 57$ & 1047 & 1st: obstruction & Restenting (1047) & $\begin{array}{l}\text { No operation; AS at } \\
\text { day } 1047\end{array}$ & Yes & No & NA & NA \\
\hline $\mathrm{M} / 66$ & $\begin{array}{l}284 \text { (1st US), } 777 \\
\text { (2nd US) }\end{array}$ & $\begin{array}{l}\text { 1st: obstruction, } \\
\text { broken S }\end{array}$ & Restenting (284) & $\begin{array}{l}\text { No operation; AS at } \\
\text { day } 284 \text { and } 777\end{array}$ & Yes & No & NA & NA \\
\hline $\mathrm{M} / 58$ & $\begin{array}{l}685 \text { (1st US), > } 225 \\
\text { (2nd US) }\end{array}$ & 1st: obstruction & Restenting (685) & $\begin{array}{l}\text { No operation; AS at } \\
\text { day } 685 \text { and } 225\end{array}$ & Yes & No & NA & NA \\
\hline $\mathrm{M} / 73$ & $\begin{array}{l}\text { 21(1st US), > } 169 \\
\text { (2nd US) }\end{array}$ & 1st: migration & Restenting (21) & Two-stage (day 190) & Yes & No & $\begin{array}{l}\text { Transverse colon } \\
\text { loop colostomy }\end{array}$ & Yes \\
\hline $\mathrm{M} / 55$ & $\begin{array}{l}155 \text { (1st US), } 155 \\
\text { (2nd CS), } 192 \text { (3rd } \\
\text { CS), (4th CS) }\end{array}$ & $\begin{array}{l}\text { 1st: obstruction, TH } \\
\text { 2nd: migration 3rd: } \\
\text { anal pain }\end{array}$ & Restenting (155) & $\begin{array}{l}\text { No operation; AS } \\
\text { at day } 155,155, \\
\text { and } 256\end{array}$ & Yes & No & NA & NA \\
\hline $\mathrm{M} / 57$ & $>197$ & - & $\mathrm{N}$ & $\begin{array}{l}\text { No operation; AS at } \\
\text { day } 197\end{array}$ & No & Yes & NA & NA \\
\hline $\mathrm{M} / 43$ & $\begin{array}{l}399 \text { (1st US), > } 11 \\
\text { (2nd CS) }\end{array}$ & 1st: obstruction, TH & Restenting (399) & $\begin{array}{l}\text { Single-stage (day } \\
410)\end{array}$ & Yes & No & $\begin{array}{l}\text { Segmental resec- } \\
\text { tion with primary } \\
\text { anastomosis }\end{array}$ & No \\
\hline $\mathrm{M} / 89$ & $>51$ & - & $\mathrm{N}$ & $\begin{array}{l}\text { No operation; AS at } \\
\text { day } 51\end{array}$ & No & Yes & NA & NA \\
\hline $\mathrm{M} / 45$ & $\begin{array}{l}2 \text { (1st US), } 2 \text { (2nd } \\
\text { CS), } 2 \text { (3rd US) }\end{array}$ & $\begin{array}{l}\text { 1st, } 2 \text { nd, 3rd: stent } \\
\text { migration }\end{array}$ & Restenting (2) & Two-stage (day 6) & Yes & No & $\begin{array}{l}\text { Transverse colon } \\
\text { loop colostomy }\end{array}$ & Yes \\
\hline $\mathrm{M} / 51$ & $>180$ & - & $\mathrm{N}$ & $\begin{array}{l}\text { No operation; AS at } \\
\text { day } 180\end{array}$ & No & Yes & NA & No \\
\hline $\mathrm{M} / 70$ & $\begin{array}{l}196 \text { (1st US), } 12 \\
\text { (2nd US), 95 (3rd } \\
\text { US), >757 (4th US) }\end{array}$ & $\begin{array}{l}\text { 1st: obstruction, TH } \\
\text { 2nd, 3rd: obstruc- } \\
\text { tion }\end{array}$ & Restenting (196) & $\begin{array}{l}\text { No operation; AS } \\
\text { at day } 196,12,95, \\
\text { and } 757\end{array}$ & Yes & No & NA & No \\
\hline $\mathrm{M} / 72$ & $>574$ & - & $\mathrm{N}$ & $\begin{array}{l}\text { No operation; AS at } \\
\text { day } 574\end{array}$ & No & Yes & NA & No \\
\hline
\end{tabular}

Table 3. Stent placement follow-up outcomes. AS: asymptomatic, S: stent, N: none, NA: not applicable, Twostage: colostomy/ileostomy with stoma, Single-stage: colectomy $\mathrm{w} / 1^{\circ}$ anastomosis.

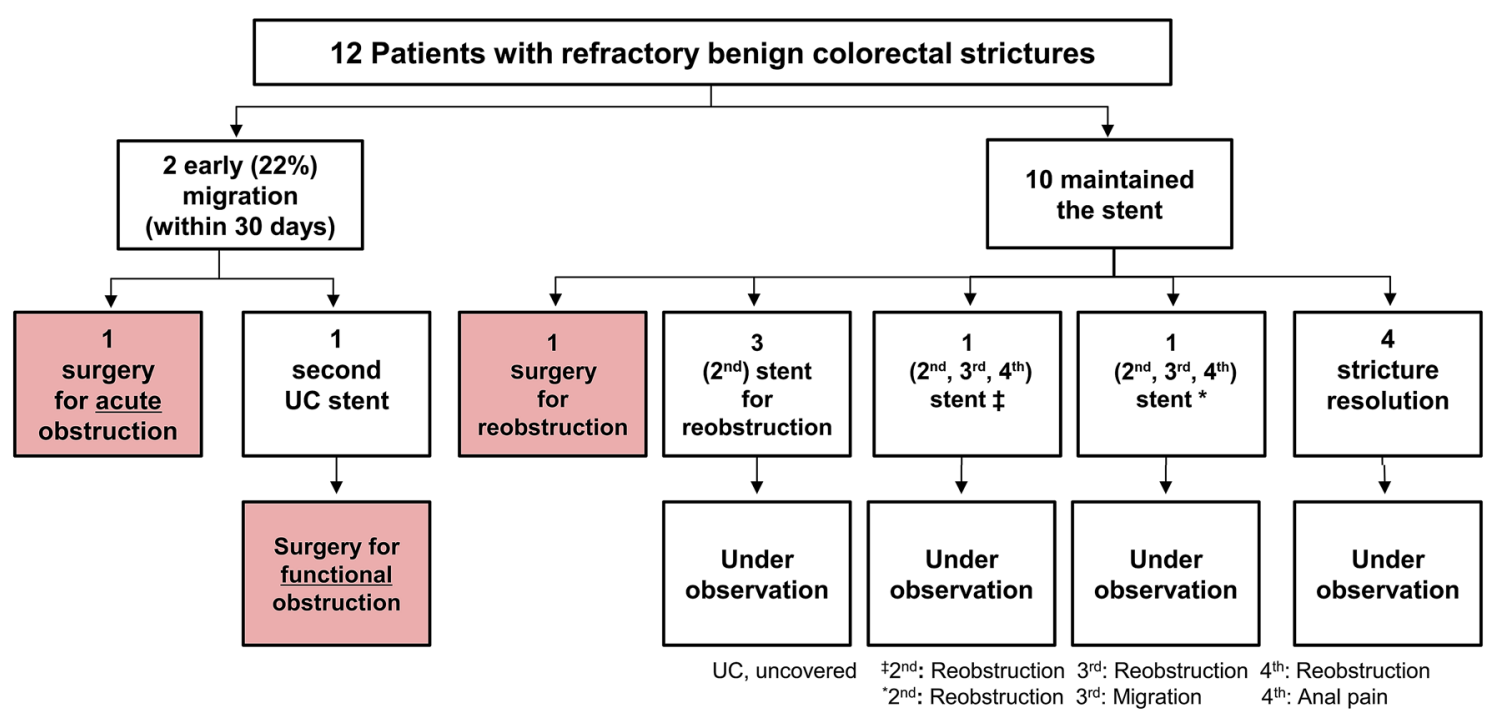

Figure 3. Study flowchart.

there have been few attempts to use uncovered stents for the treatment of benign strictures, and related reports and follow-up data have been markedly limited.

The present study investigated the efficacy and safety of UCSEMSs for refractory post-anastomotic strictures in a highly select patient group. Among the strengths of this study, the first is that it examined stent efficacy in a single group of patients in whom obstruction had been caused by a post-anastomotic stricture. Second, it included a refractory group of patients who were not responsive to conventional endoscopic treatment. Finally, we investigated the effectiveness and safety of UCSEMS placement in the aforementioned group. To the best of our knowledge, this is the first study to attempt UCSEMS placement in a homogeneous group of patients with refractory anastomotic strictures. 
a

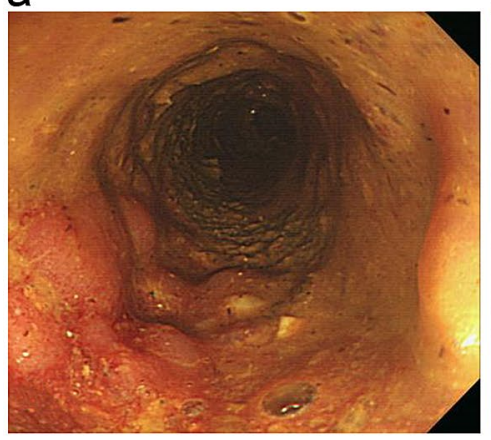

b

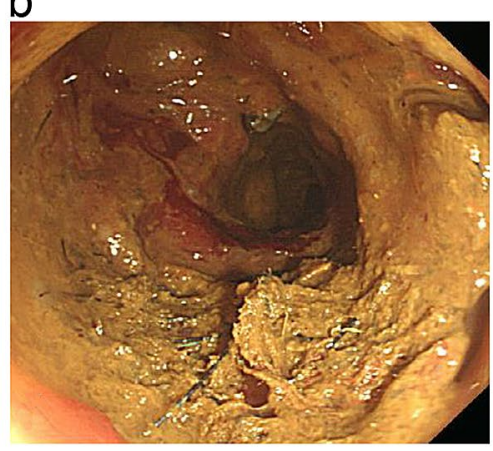

$\mathrm{C}$

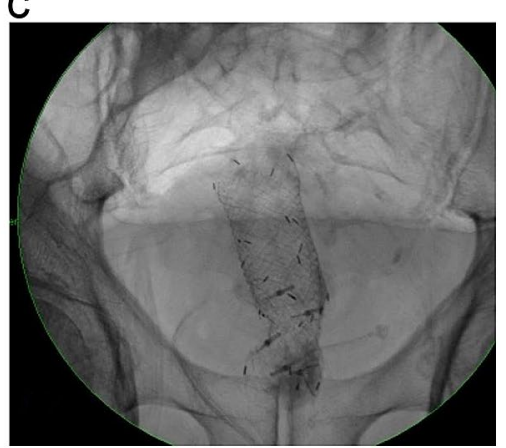

Figure 4. Patient with endoscopic stent patency who underwent surgery due to worsening obstructive symptoms. (a) Successful insertion of the second uncovered stent after the migration of the first stent. (b,c) Stent patency maintained in the endoscopy that was re-performed due to worsening obstructive symptoms.

The effectiveness of SEMSs has mostly been dependent on the etiology of the stricture ${ }^{16,18,29,34-36}$. Stents have been effective in cases of postsurgical colorectal strictures, whereas they have been deemed inappropriate in cases of ischemic strictures, diverticular strictures, and Crohn's disease ${ }^{20}$. Therefore, evaluating the effects of stents on strictures in a homogeneous group with a similar etiology is imperative. However, most studies on benign colorectal strictures involve a variety of etiologies.

Benign anastomotic strictures of the rectosigmoid colon that fail to respond to repeated endoscopic dilation attempts may represent potential indications for stent placement. Although biodegradable and drug-eluting stents have also been recently studied, or their placement has been attempted, they have not shown satisfactory results, and information regarding their use in the lower gastrointestinal tract has remained limited ${ }^{21-25,37}$. Despite their considerable advantages, current biodegradable stents have not yet been widely used, and access to these stents is limited in many countries. Furthermore, biodegradable stents specially designed for colonic strictures are not yet available. In cases where treatment with stents for benign colorectal strictures fails, other investigational or surgical treatments are considered ${ }^{27}$. However, surgical revision, such as stoma diversion, may be very difficult because of adhesion, stricture, and local inflammation frequently located in the lower rectum, and the results are often suboptimal, particularly in emergency situations ${ }^{4}$. Moreover, specific indications for FCSEMSs and UCSEMSs in benign colorectal stenosis have not been well established. Therefore, although UCSEMS can no longer be endoscopically removed, and there are limited data on the real risk of maintaining a UCSEMS in the colon for a prolonged period, the inclusion of patients with refractory colorectal stricture in the present study is of significant importance. This is particularly relevant given that UCSEMSs offer an alternative option, and help avoid invasive surgical treatments for patients who are not suitable for surgery because of morbidity or adhesion $^{38}$.

Small et al. reported complications, including migration, reobstruction, and perforation, in 38\% (9/23) of cases involving benign colorectal strictures that were treated with uncovered stent insertion ${ }^{17}$. For this reason, FCSEMSs have been primarily used for benign strictures. However, data regarding the safety and efficacy of UCSEMSs have been obtained from patient groups with heterogeneous etiology. Among the 23 patients included in the study conducted by Small et al., only three had postsurgical anastomotic strictures. Furthermore, postoperative strictures caused complications in only one case, with migration being the major complication, while the remaining two patients were asymptomatic for 1 and 10 months without complications. Moreover, the median follow-up period was only 6 months. Other studies have also revealed relatively favorable results for SEMS among patients with post-anastomotic strictures ${ }^{20,35}$.

Studies of FCSEMS in benign anastomotic strictures have shown a clinical success rate of approximately $36-71.4 \%$, with most complications being caused by migration ${ }^{19,39-41}$. UCSEMSs have a lower rate of migration than covered stents; however, compared with covered stents, uncovered stents are subject to tissue hyperplasia when used for a prolonged period of time. Uncovered stents are normally impossible to remove because of the hyperplastic reaction, and can only be removed surgically. Because of these disadvantages, uncovered stents have not been used for benign strictures given concerns regarding morbidity. Finally, surgical treatment may be required for patients who fail endoscopic remediation. However, for patients who are considered to be even unfit to undergo surgery, other treatment options will have to be explored. Therefore, it is also necessary to examine the effectiveness and safety of UCSEMSs in patients with post-anastomosis strictures who showed relatively favorable outcomes after stent treatment in previous studies. As yet, there has been a paucity of studies on this topic; nonetheless, the significant findings of the present study suggest that UCSEMSs are a potential singletreatment option in specific groups.

Other significant findings presented herein include follow-up data on UCSEMSs for refractory benign anastomotic colorectal strictures. In one case report of a patient with a benign colorectal stricture, Monzur et al. revealed that long-term UCSEMS placement proved to be a reliable treatment option for over 4 years ${ }^{1}$. The clinical course of the patient was complicated by recurrent episodes of hematochezia, which is consistent with the increased risk of gastrointestinal bleeding associated with prolonged SEMS use. However, no UCSEMS-related bleeding was observed in our study, and technical success was achieved in all cases. The early clinical success rate was also high, with relief of obstructive symptoms observed in $>92 \%$ of the patients. These results are noteworthy 
given that in all patients in the study population, there was failure to obtain temporary drainage using covered SEMSs or endoscopic balloon dilations, and such cases would typically be difficult to manage. Under these circumstances, such refractory strictures may require surgical revision. However, if other endoscopic treatments, such as covered, removable, or biodegradable stents, fail, and if the patient is not fit to undergo surgery, UCSEMS placement may be considered to avoid further surgical treatment in the short term. Accordingly, our results suggest that UCSEMS placement for the treatment of refractory benign colorectal anastomotic strictures may be considered in selected patients. However, the limited number of patients included in this study, as well as the study design, may prevent us from drawing definitive conclusions. At the median follow-up period of 16.7 months, only 4 (25\%) of the 12 patients had achieved clinical success. As expected, the reobstruction rate was high, with stent reobstruction occurring in $>50 \%$ of the patients. Nonetheless, our experience suggests that the duration of stent placement was sufficient to attain a clinical medium-term symptom resolution (461 [range: 155-1047] days). These outcomes show that UCSEMSs can be used as a bridge to therapy preoperatively, or as a palliative therapy in patients unfit for surgery if other endoscopic treatments are found to be ineffective against refractory benign colorectal strictures. Even if reobstruction occurs, the stent can be reinserted to alleviate the symptoms and maintain stent patency.

Considering that the long-term safety and efficacy of UCSEMSs as a permanent therapy remains to be determined, data for long-term UCSEMS placement are still unavailable. More research is required to validate the long-term safety and efficacy of UCSEMSs in refractory benign colorectal strictures.

In the present study, two patients who underwent UCSEMS placement exhibited stent migration. In one case, the patient had undergone balloon dilation nine times, and endoscopic transanal resection once prior to stent placement. All instances of stent migration occurred in cases with partial intestinal obstruction since the time of diagnosis, wherein obstructive symptoms might have resulted from a nonfunctioning bowel rather than from an obstruction. In such cases, the prognosis of stent insertion was projected to be poor. Therefore, surgical treatment can be considered from the very beginning in patients with refractory anastomotic strictures due to partial obstruction.

Perforation, which remains one of the most serious complications of stent placement, usually occurs immediately after stent placement. Moreover, rapid stent expansion, balloon predilatation, and excessive stricture manipulation have been shown to increase the risk of perforation ${ }^{42-44}$, with radiation-induced strictures being particularly vulnerable to injury. The high incidence of complications seems to be related to the aforementioned factors ${ }^{35,45}$. Although the patients in the current study displayed some risk factors, such as radiation and balloon predilatation, no UCSEMS-related perforation occurred.

The present study has limitations such as the small sample size (21 procedures in 12 patients) and the retrospective design. Moreover, the rate of complications in the present study was high (75\%). Even though data were prospectively collected, the study was performed retrospectively with no control group. However, no comparable standard treatment exists for refractory colorectal strictures through which a control group can be established, and recruitment limitations led to an insufficient number of patients for a prospective randomized trial in a single-center setting.

Despite these limitations, among similar studies conducted to date, this study included the largest homogeneous group of patients with refractory benign anastomotic strictures to evaluate the effectiveness and safety of UCSEMS placement. Follow-up data concerning UCSEMS placement in patients with benign refractory strictures are very limited, with no follow-up being performed for most cases after UCSEMS placement. The median followup period after UCSEMS placement was 16.7 (range, 1.7-35.37) months in this study. With a medium-term follow-up period, this study provides a unique perspective on the efficacy of this endoscopic option over time.

In conclusion, UCSEMS placement for symptomatic refractory benign anastomotic strictures may be selected on an individual basis, taking into account the comorbidity, estimated life expectancy of the patient, or before permanent colostomy for patients who have contraindications to or refuse permanent colostomy. Furthermore, patients should be counseled very carefully regarding the likely necessity of repeating the procedures. However, despite the high reobstruction rate, UCSEMS may be able to achieve uncomplicated medium-term symptom relief and avoid more invasive surgical treatments, such as stoma diversion, thereby improving patients' quality of life. Prior to surgical or experimental approaches, UCSEMS placement may be considered as a treatment option for post-anastomotic strictures in selected patients who are non-responsive to conventional endoscopic treatments and are considered unfit to undergo surgery. Surgical treatment may be considered from the beginning in patients in whom post-anastomotic strictures remain unresponsive to endoscopic treatment owing to partial obstruction, given that their symptoms are attributable to a nonfunctioning bowel. Our experience verifies that UCSEMS may be used as a last resort treatment option in patients with an otherwise poor prognosis, or who have no alternatives.

Received: 30 May 2019; Accepted: 28 October 2020

Published online: 16 November 2020

\section{References}

1. Monzur, F., Lewis, A. \& Buscaglia, J. M. Uncovered self-expanding metal stent (SEMS) four years after placement for long-term treatment of a benign colonic obstruction. ACG Case Rep. J. 1, 206 (2014).

2. Bannura, G. C. et al. Predictive factors of stenosis after stapled colorectal anastomosis: Prospective analysis of 179 consecutive patients. World J. Surg. 28, 921-925 (2004).

3. Shimada, S. et al. A new device for the treatment of coloproctostomic stricture after double stapling anastomoses. Ann. Surg. 224, 603 (1996).

4. Schlegel, R. D., Dehni, N., Parc, R., Caplin, S. \& Tiret, E. Results of reoperations in colorectal anastomotic strictures. Dis. Colon Rectum 44, 1464-1468 (2001). 
5. Mirnezami, A. et al. Increased local recurrence and reduced survival from colorectal cancer following anastomotic leak: Systematic review and meta-analysis. Ann. Surg. 253, 890-899 (2011).

6. Suchan, K., Muldner, A., Manegold, B. J. S. E. \& Techniques, O. I. Endoscopic treatment of postoperative colorectal anastomotic strictures. Surg. Endosc. 17, 1110-1113 (2003).

7. Banerjee, A. K., Walters, T. K., Wilkins, R. \& Burke, M. Wire-guided balloon coloplasty-a new treatment for colorectal strictures?. J. R. Soc. Med. 84, 136-139 (1991).

8. Delaunay-Tardy, K., Barthélémy, C., Dumas, O., Balique, J. G. \& Audigier, J. C. Endoscopic therapy of benign colonic post-operative strictures. Gastroenterol. Clin. Biol. 27, 610-613 (2003).

9. Johansson, C. Endoscopic dilation of rectal strictures. Dis. Colon Rectum 39, 423-428 (1996).

10. Linares, L. et al. Natural history and treatment of anorectal strictures complicating Crohn's disease. Br. J. Surg. 75, 653-655 (1988).

11. Forshaw, M., Maphosa, G., Sankararajah, D., Parker, M. \& Stewart, M. Endoscopic alternatives in managing anastomotic strictures of the colon and rectum. Tech. Coloproctol. 10, 21-27 (2006).

12. Feo, L. \& Schaffzin, D. M. Colonic stents: The modern treatment of colonic obstruction. Adv. Ther. 28, 73-86 (2011).

13. Guan, Y.-S., Sun, L., Li, X. \& Zheng, X.-H. Successful management of a benign anastomotic colonic stricture with self-expanding metallic stents: A case report. World J. Gastroenterol. 10, 3534 (2004).

14. García-Cano, J. Colorectal stenting as first-line treatment in acute colonic obstruction. World J. Gastrointest. Endosc. 5, 495 (2013).

15. Davidson, R. \& Sweeney, W. Endoluminal stenting for benign colonic obstruction. Surg. Endosc. 12, 353-354 (1998).

16. Forshaw, M., Sankararajah, D., Stewart, M. \& Parker, M. Self-expanding metallic stents in the treatment of benign colorectal disease: Indications and outcomes. Colorectal Dis. 8, 102-111 (2006).

17. Small, A., Young-Fadok, T. \& Baron, T. Expandable metal stent placement for benign colorectal obstruction: Outcomes for 23 cases. Surg. Endosc. 22, 454-462 (2008).

18. Rayhanabad, J. \& Abbas, M. A. Long-term outcome of endoscopic colorectal stenting for malignant and benign disease. Am. Surg. 75, 897-900 (2009).

19. Dai, Y., Chopra, S. S., Wysocki, W. M. \& Hünerbein, M. Treatment of benign colorectal strictures by temporary stenting with selfexpanding stents. Int. J. Colorectal Dis. 25, 1475-1479 (2010).

20. Keränen, I., Lepistö, A., Udd, M., Halttunen, J. \& Kylänpää, L. Outcome of patients after endoluminal stent placement for benign colorectal obstruction. Scand. J. Gastroenterol. 45, 725-731 (2010).

21. Janík, V., Horák, L., Hnaníček, J., Málek, J. \& Laasch, H. U. Biodegradable polydioxanone stents: A new option for therapy-resistant anastomotic strictures of the colon. Eur. Radiol. 21, 1956 (2011).

22. Mullan, D., O’Dwyer, S. T. \& Laasch, H. U. Benign anastomotic stricture of the rectum complicated by metal stent insertion: Salvage by placement of a biodegradable polydioxanone stent. Gastrointest. Interv. 2, 59-61 (2013).

23. Najran, P. S., Mullan, D. \& Laasch, H. U. Biodegradable stent insertion for ischaemic colorectal strictures: Tiger country. Gastrointest. Interv. 6, 145-147 (2017).

24. Rejchrt, S., Kopacova, M., Brozik, J. \& Bures, J. J. E. Biodegradable stents for the treatment of benign stenoses of the small and large intestines. Endoscopy 43, 911-917 (2011).

25. Rodrigues, C., Oliveira, A., Santos, L., Pires, E. \& Deus, J. Biodegradable stent for the treatment of a colonic stricture in Crohn's disease. World J. Gastrointest. Endosc. 5, 265 (2013).

26. Kim, E. J. \& Kim, Y. J. Stents for colorectal obstruction: Past, present, and future. World J. Gastroenterol. 22, 842 (2016).

27. Kwon, Y. H., Jeon, S. W. \& Lee, Y. K. Endoscopic management of refractory benign colorectal strictures. Clin. Endosc. 46, 472 (2013).

28. Geiger, T. M., Miedema, B. W., Tsereteli, Z., Sporn, E. \& Thaler, K. Stent placement for benign colonic stenosis: Case report, review of the literature, and animal pilot data. Int. J. Colorectal Dis. 23, 1007-1012 (2008).

29. Meisner, S., Hensler, M., Knop, F. K., West, F. \& Wille-Jørgensen, P. Self-expanding metal stents for colonic obstruction: Experiences from 104 procedures in a single center. Dis. Colon Rectum 47, 444-450 (2004).

30. Sagar, J. Colorectal stents for the management of malignant colonic obstructions. Cochrane Database Syst. Rev. 11, CD007378 (2011).

31. Saida, Y. et al. Outcome of 141 cases of self-expandable metallic stent placements for malignant and benign colorectal strictures in a single center. Surg. Endosc. 25, 1748-1752 (2011).

32. Bae, J.-I., Shin, J. H., Song, H.-Y. \& Lee, G. H. Treatment of a benign anastomotic duodenojejunal stricture with a polytetrafluoroethylene-covered retrievable expandable nitinol stent. J. Vasc. Interv. Radiol. 15, 769-772 (2004).

33. Kim, J. H. et al. Early symptomatic strictures after gastric surgery: Palliation with balloon dilation and stent placement. J. Vasc. Interv. Radiol. 19, 565-570 (2008).

34. Suzuki, N. et al. Colorectal stenting for malignant and benign disease: Outcomes in colorectal stenting. Dis. Colon Rectum 47, 1201-1207 (2004).

35. Paúl, L., Pinto, I., Gómez, H., Fernández-Lobato, R. \& Moyano, E. Metallic stents in the treatment of benign diseases of the colon: Preliminary experience in 10 cases. Radiology 223, 715-722 (2002).

36. Bertelsen, C., Meisner, S., West, F. \& Wille-Jørgensen, P. Treatment of colorectal obstruction with self-expanding metal stents. Ugeskr. Laeger 168, 907-911 (2006).

37. Repici, A. et al. A retrospective analysis of early and late outcome of biodegradable stent placement in the management of refractory anastomotic colorectal strictures. Surg. Endosc. 27, 2487-2491 (2013).

38. Dormann, A., Deppe, H. \& Wigginghaus, B. Self-expanding metallic stents for continuous dilatation of benign stenoses in gastrointestinal tract-first results of long-term follow-up in interim stent application in pyloric and colonic obstructions. Zeitschrift für Gastroenterologie 39, 957-960 (2001).

39. Cereatti, F. et al. Fully covered self-expandable metal stent in the treatment of postsurgical colorectal diseases: Outcome in 29 patients. Ther. Adv. Gastroenterol. 9, 180-188 (2016).

40. Caruso, A. et al. Fully covered self-expanding metal stents for refractory anastomotic colorectal strictures. Ther. Adv. Gastroenterol. 29, 1175-1178 (2015).

41. Cooper, C. J., Morales, A. \& Othman, M. O. Outcomes of the use of fully covered esophageal self-expandable stent in the management of colorectal anastomotic strictures and leaks. Diagn. Ther. Endosc. 2014, 187541 (2014).

42. Adler, D. G. \& Baron, T. H. Endoscopic palliation of colorectal cancer. Hematol. Oncol. Clin. N. Am. 16, 1015-1029 (2002).

43. Sebastian, S., Johnston, S., Geoghegan, T., Torreggiani, W. \& Buckley, M. Pooled analysis of the efficacy and safety of self-expanding metal stenting in malignant colorectal obstruction. Am. J. Gastroenterol. 99, 2051 (2004).

44. Baron, T. H., Dean, P. A., Yates, M. R. III., Canon, C. \& Koehler, R. E. Expandable metal stents for the treatment of colonic obstruction: Techniques and outcomes. Gastrointest. Endosc. 47, 277-286 (1998).

45. Yates, M. R. \& Baron, T. H. Treatment of a radiation-induced sigmoid stricture with an expandable metal stent. Gastrointest. Endosc. 50, 422-426 (1999). 


\section{Acknowledgements}

Ji Taek Hong carried out the acquisition, analysis, and interpretation of data. Ji Taek Hong wrote and drafted the manuscript. Tae Jun Kim, Sung Noh Hong, Young-Ho Kim, and Dong Kyung Chang critically revised the manuscript for important intellectual content. All authors approved the final submission of the manuscript.

\section{Author contributions}

Conceptualization: E.R.K. Methodology: J.T.H., E.R.K., and T.J.K. Formal analysis: J.T.H. and T.J.K. Project administration: J.T.H. Visualization: Y.H.K. and D.K.C. Writing-original draft: J.T.H. Writing-review and editing: S.N.H., Y.H.K., D.K.C., and E.R.K. Approval of final manuscript: All authors.

\section{Competing interests}

The authors declare no competing interests.

\section{Additional information}

Correspondence and requests for materials should be addressed to E.R.K.

Reprints and permissions information is available at www.nature.com/reprints.

Publisher's note Springer Nature remains neutral with regard to jurisdictional claims in published maps and institutional affiliations.

(c) (i) Open Access This article is licensed under a Creative Commons Attribution 4.0 International License, which permits use, sharing, adaptation, distribution and reproduction in any medium or format, as long as you give appropriate credit to the original author(s) and the source, provide a link to the Creative Commons licence, and indicate if changes were made. The images or other third party material in this article are included in the article's Creative Commons licence, unless indicated otherwise in a credit line to the material. If material is not included in the article's Creative Commons licence and your intended use is not permitted by statutory regulation or exceeds the permitted use, you will need to obtain permission directly from the copyright holder. To view a copy of this licence, visit http://creativecommons.org/licenses/by/4.0/.

(c) The Author(s) 2020 